\title{
Myelodysplastic syndromes and overlap syndromes
}

\author{
Yoon Hwan Chang \\ Department of Laboratory Medicine, Seoul National University Hospital, Seoul, Korea
}

p-ISSN 2287-979X / e-ISSN 2288-0011

https://doi.org/10.5045/br.2021.2021010

Blood Res 2021;56:S51-S64.

Received on January 18, 2021

Revised on March 9, 2021

Accepted on March 10, 2021

\begin{abstract}
Myelodysplastic syndromes (MDS) are a heterogeneous group of clonal hematological neoplasms characterized by ineffective hematopoiesis, morphologic dysplasia, and cytopenia. MDS overlap syndromes include various disorders, such as myelodysplastic/myeloproliferative neoplasms and hypoplastic MDS with aplastic anemia characteristics. MDS overlap syndromes share the characteristics of other diseases, which make differential diagnoses challenging. Advances in genomic studies have led to the discovery of frequent mutations in MDS and overlap syndromes; however, most of the mutations are not specific for the diagnosis of these diseases. The molecular characteristics of the overlap syndromes usually do not show a just "in-between" form but rather heterogeneous features. Established diagnostic criteria for these diseases based on clinical, morphologic, and laboratory features are still useful when combined with genomic data. It is expected that further studies for MDS and overlap syndromes will place emphasis on the roles of mutations as therapeutic targets and prognostic indicators.
\end{abstract}

Key Words Myelodysplastic syndromes, Overlap syndromes, Myelodysplastic/myeloproliferative neoplasms, Hypoplastic MDS, Genomic, Mutation

\section{INTRODUCTION}

Myelodysplastic syndromes (MDS) are a heterogeneous group of clonal hematological neoplasms characterized by ineffective hematopoiesis, manifesting as morphologic dysplasia of hematopoietic cells and peripheral cytopenia [1-3].

Several benign or malignant conditions show morphologic features and characteristics similar to MDS and MDS overlap syndromes, often making it difficult to diagnose patients correctly [4]. These MDS overlap syndromes include myelodysplastic/myeloproliferative neoplasms (MDS/MPNs) with both MDS and MPN features and hypoplastic MDS (hMDS) with aplastic anemia (AA) characteristics. In addition, MDS overlap syndromes may include secondary acute myeloid leukemia (AML) evolving from MDS, and some potential pre-MDS conditions showing cytopenia or somatic mutations but not meeting the diagnostic criteria of the MDS. However, secondary AML and potential pre-MDS states are regarded as a "continuation" or "transformation" from or into the MDS and, thus, have not been discussed in this review. This needs to be discussed as a separate topic in terms of a continuous spectrum.

The present article will provide insights into correct differ- ential diagnoses through comparative reviews for the diagnostic criteria and genetic findings of these MDS and overlap syndromes.

\section{Myelodysplastic syndromes}

The revised 4th edition of the World Health Organization (WHO) Classification of Myeloid Neoplasms (2016) introduced refined diagnostic information for MDS subtypes (Table 1) [1, 3, 5, 6].

The terminology for adult MDS was changed in the 2016 WHO Classification and terms, such as "refractory anemia" and "refractory cytopenia," were replaced with "myelodysplastic syndrome" followed by the appropriate modifiers: single vs multilineage dysplasia, ring sideroblasts (RS), excess blasts, or the del(5q) cytogenetic abnormality [1]. There were no changes in the classification of childhood MDS; refractory cytopenia of childhood remains a provisional entity within this category [1].

The category of 'Refractory cytopenias with multilineage dysplasia and ring sideroblasts (RCMD-RS)' was eliminated in the 2008 WHO Classification and was merged with RCMD because it was shown to be prognostically similar to RCMD, but lacking RS [7-9]. The discovery of mutations in the spliceosome gene $S F 3 B 1$ that are associated with RS provided 
Table 1. Diagnostic criteria for myelodysplastic syndrome (MDS) entities [5, 6].

\begin{tabular}{|c|c|c|c|c|c|}
\hline Name & $\begin{array}{l}\text { Dysplastic } \\
\text { lineages }\end{array}$ & Cytopenias $^{\text {a) }}$ & $\operatorname{RS}(\%)^{b}$ & BM and PB blasts (\%) & Cytogenetics $^{\mathrm{c})}$ \\
\hline MDS-SLD & 1 & 1 or 2 & $<15 /<5^{\mathrm{d})}$ & $\begin{array}{c}\mathrm{BM}<5, \mathrm{~PB}<1 \\
\text { no Auer rods }\end{array}$ & $\begin{array}{l}\text { Any, unless fulfills all criteria for } \\
\text { MDS with isolated del }(5 q)\end{array}$ \\
\hline MDS-MLD & 2 or 3 & $1-3$ & $<15 /<5^{\mathrm{d})}$ & $\begin{array}{c}\mathrm{BM}<5, \mathrm{~PB}<1 \\
\text { no Auer rods }\end{array}$ & $\begin{array}{l}\text { Any, unless fulfills all criteria for } \\
\text { MDS with isolated del }(5 q)\end{array}$ \\
\hline \multicolumn{6}{|l|}{ MDS-RS } \\
\hline MDS-RS-SLD & 1 & 1 or 2 & $\geq 15 / \geq 5^{\mathrm{d})}$ & $\begin{array}{c}\mathrm{BM}<5, \mathrm{~PB}<1 \\
\text { no Auer rods }\end{array}$ & $\begin{array}{l}\text { Any, unless fulfills all criteria for } \\
\text { MDS with isolated del }(5 q)\end{array}$ \\
\hline MDS-RS-MLD & 2 or 3 & $1-3$ & $\geq 15 / \geq 5^{\mathrm{d})}$ & $\begin{array}{c}\mathrm{BM}<5, \mathrm{~PB}<1 \\
\text { no Auer rods }\end{array}$ & $\begin{array}{l}\text { Any, unless fulfills all criteria for } \\
\text { MDS with isolated del }(5 q)\end{array}$ \\
\hline MDS with isolated del(5q) & $1-3$ & $1-2$ & None or any & $\begin{array}{c}\mathrm{BM}<5, \mathrm{~PB}<1 \\
\text { no Auer rods }\end{array}$ & $\begin{array}{l}\text { del }(5 q) \text { alone or with } 1 \text { additional } \\
\text { abnormality except }-7 \text { or del( } 7 q)\end{array}$ \\
\hline \multicolumn{6}{|l|}{ MDS-EB } \\
\hline MDS-EB-1 & $0-3$ & $1-3$ & None or any & $\begin{array}{l}\text { BM 5-9 or PB 2-4, } \\
\text { no Auer rods }\end{array}$ & Any \\
\hline MDS-EB-2 & $0-3$ & $1-3$ & None or any & $\begin{array}{l}\text { BM 10-19 or PB 5-19 } \\
\text { or Auer rods }\end{array}$ & Any \\
\hline \multicolumn{6}{|l|}{ MDS-U } \\
\hline $1 \%$ blood blasts & $1-3$ & $1-3$ & None or any & $\begin{array}{c}\mathrm{BM}<5, \mathrm{~PB}=1^{\mathrm{e})} \\
\text { no Auer rods }\end{array}$ & Any \\
\hline SLD and pancytopenia & 1 & 3 & None or any & $\begin{array}{c}\mathrm{BM}<5, \mathrm{~PB}<1 \\
\text { no Auer rods }\end{array}$ & Any \\
\hline $\begin{array}{l}\text { Defining cytogenetic } \\
\text { abnormality }\end{array}$ & 0 & $1-3$ & $<15^{\mathrm{f}}$ & $\begin{array}{c}\mathrm{BM}<5, \mathrm{~PB}<1 \\
\text { no Auer rods }\end{array}$ & MDS-defining abnormality ${ }^{\mathrm{g}}$ \\
\hline $\begin{array}{l}\text { Refractory cytopenia of } \\
\text { childhood }\end{array}$ & $1-3$ & $1-3$ & None & $\mathrm{BM}<5, \mathrm{~PB}<2$ & Any \\
\hline
\end{tabular}

${ }^{a)}$ Cytopenias defined as hemoglobin concentration $<10 \mathrm{~g} / \mathrm{dL}$, platelet count $<100 \times 10^{9} / \mathrm{L}$, and absolute neutrophil count $<1.8 \times 10^{9} / \mathrm{L}$, although MDS can present with mild anemia or thrombocytopenia above these levels; PB monocytes must be $<1 \times 10^{9} / \mathrm{L}$. ${ }^{\mathrm{b}}{ }^{\mathrm{R}}$ Ring sideroblasts as the percentage of marrow erythroid elements. ${ }^{\mathrm{c}}$ Cytogenetics by conventional karyotype analysis. ${ }^{\mathrm{d}}$ If $S F 3 B 1$ mutation is present. ${ }^{\mathrm{e}} 1 \% \mathrm{~PB}$ blasts must be recorded on $\geq 2$ separate occasions. ${ }^{f}$ Cases with $\geq 15 \%$ ring sideroblasts by definition have significant erythroid dysplasia and are classified as MDS-RS-SLD. ${ }^{\mathrm{g}}$ See Table 2.

Abbreviations: BM, bone marrow; EB, excess blasts; MDS-U, MDS, unclassifiable; MLD, multilineage dysplasia; PB, peripheral blood; RS, ring sideroblasts; SLD, single lineage dysplasia.

a link between morphology and genetics in MDS [9-12]. This combination of shared morphology (RS) and a shared underlying driver mutation (SF3B1) favors the separation of MDS with RS as distinct entities, which may have single or multilineage dysplasia [9]. Therefore, in the 2016 WHO Classification, the subtype 'RCMD-RS' was restored as 'MDS with ring sideroblasts and multilineage dysplasia (MDSRS-MLD)' [13]. It has been shown that in cases of MDS with RS, the actual percentage of RS is not prognostically relevant $[1,11]$. Therefore, according to the $2016 \mathrm{WHO}$ classification, if an SF3B1 mutation is identified, a diagnosis of MDS-RS may be established if RS comprise as few as $5 \%$ of the nucleated erythroid cells, whereas at least $15 \%$ $\mathrm{RS}$ are still required in cases lacking a demonstrable $S F 3 B 1$ mutation [1].

In cases with refractory, unexplained cytopenia but no morphological evidence of dysplasia or increased blasts, cytogenetic abnormalities listed in Table 2 (the same MDS-defining cytogenetic abnormalities listed in the 2008 WHO classification) are considered as presumptive evidence of MDS, and such cases are included in the category of MDS, unclassifiable $[5,14]$. In such cases, the abnormality must be demonstrated by conventional karyotyping, not by fluorescence in situ hybridization (FISH) or sequencing technologies [1].

A very minor change in MDS with isolated del(5q) is the inclusion of one additional chromosomal abnormality (e.g., +8), but excluding monosomy $7[13,15,16]$. Clinical studies have not demonstrated any adverse impact of an extra chromosome on response to lenalidomide therapy [13].

Recurrent cytogenetic abnormalities identified by conventional karyotyping are found in approximately 50\% of MDS cases (Table 2) [5, 17-19]. In contrast to the case with AML, in which balanced abnormalities, such as $\mathrm{t}(8 ; 21)(\mathrm{q} 22 ; \mathrm{q} 22)$, are predominant $[17,19]$, the majority of the abnormalities in MDS are unbalanced changes, which result in copy-number abnormalities (CNAs), such as gains or losses of chromosomal materials $[17,20]$. Complex karyotypes (3 or more chromosomal abnormalities) are frequently accompanied by TP53 mutation (approximately $40-50 \%$ cases), generally predicting adverse clinical outcomes, particularly when $-5 / \operatorname{del}(5 q)$ and $\operatorname{del}(17 p)$ are involved [17, 21-23].

Single nucleotide polymorphism (SNP) array-based platforms can detect CNAs and copy-neutral loss of hetero- 
Table 2. Recurrent chromosomal abnormalities and their frequencies in myelodysplastic syndrome (MDS) at diagnosis [5, 14].

\begin{tabular}{|c|c|c|c|}
\hline \multirow{2}{*}{ Chromosomal abnormality } & \multicolumn{2}{|c|}{ Frequency } & \multirow{2}{*}{ Prognosis $^{\text {b) }}$} \\
\hline & MDS overall & Therapy-related MDS & \\
\hline \multicolumn{4}{|l|}{ Unbalanced } \\
\hline Gain of chromosome $8^{\mathrm{a})}$ & $10 \%$ & & Intermediate \\
\hline Loss of chromosome 7 or del(7q) & $10 \%$ & $50 \%$ & Intermediate \\
\hline $\operatorname{del}(5 q)$ & $10 \%$ & $40 \%$ & Good \\
\hline $\operatorname{del}(20 q)^{a)}$ & $5-8 \%$ & & Good \\
\hline Loss of $Y$ chromosome $e^{a)}$ & $5 \%$ & & Very good \\
\hline Isochromosome $17 q$ or del(17p) & $3-5 \%$ & $25-30 \%$ & Intermediate \\
\hline Loss of chromosome 13 or del(13q) & $3 \%$ & & Intermediate \\
\hline $\operatorname{del}(11 q)$ & $3 \%$ & & Very good \\
\hline $\operatorname{del}(12 p)$ or $t(12 p)$ & $3 \%$ & & Good \\
\hline $\operatorname{del}(9 q)$ & $1-2 \%$ & & Intermediate \\
\hline $\operatorname{idic}(X)(q 13)$ & $1-2 \%$ & & Intermediate \\
\hline \multicolumn{4}{|l|}{ Balanced } \\
\hline$t(11 ; 16)(q 23.3 ; p 13.3)$ & & $3 \%$ & Intermediate \\
\hline $\mathrm{t}(3 ; 21)(\mathrm{q} 26.2 ; \mathrm{q} 22.1)$ & & $2 \%$ & Poor \\
\hline$t(1 ; 3)(p 36.3 ; q 21.2)$ & $1 \%$ & & Poor \\
\hline $\mathrm{t}(2 ; 11)(\mathrm{p} 21 ; \mathrm{q} 23.3)$ & $1 \%$ & & Intermediate \\
\hline $\operatorname{inv}(3)(q 21.3 q 26.2) / t(3 ; 3)(q 21.3 ; q 26.2)$ & $1 \%$ & & Poor \\
\hline$t(6 ; 9)(p 23 ; q 34.1)$ & $1 \%$ & & Intermediate \\
\hline
\end{tabular}

zygosity (LOH) or uniparental disomy (UPD), which are commonly seen in chromosomes $1 \mathrm{p}, 4 \mathrm{q}, 7 \mathrm{q}, 17 \mathrm{p}$, and $21 \mathrm{q}$ in MDS, and in 7q and 11q in MDS/MPN [17, 24]. Combined with CNAs and chromosomal abnormalities, more than $78 \%$ to $90 \%$ of MDS patients have one or more known recurrent genetic abnormalities [17, 25, 26]. CNAs and mutations significantly correlate with the disease phenotype and clinical outcome [17].

Recurrent somatic mutations in more than 50 genes have been identified in $80-90 \%$ of MDS cases, and more than 30 driver genes involved in the pathogenesis of MDS have been identified $[5,17,25,26]$. The genes found to be mutated in at least $5 \%$ of MDS cases are listed in Table $3[5,27$, 28]. While a typical MDS patient harbors a median of 2 or 3 driver mutations, those with high-risk MDS (MDS with excess blasts and MDS with multilineage dysplasia) and chronic myelomonocytic leukemia (CMML) tend to show higher numbers of driver mutations than those with lower-risk MDS [MDS with single lineage dysplasia (SLD), MDS-RS-SLD, and MDS with isolated del(5q)] [17]. Mutations in several genes, such as DDX41, RUNX1, GATA2, and TP53, may be present in the germline and responsible for a predisposition to AML and MDS [17].

Some combinations of driver mutations co-occur more frequently than expected, while others are observed in a mutually exclusive manner, suggesting the presence of functional interactions between these mutations that are involved in positive and negative selections [17]. To date, $\operatorname{del}(5 \mathrm{q})$ remains the only cytogenetic or molecular genetic abnormality that defines a specific MDS subtype and isolated del(5q) is associated with anemia (with or without other cytopenias) and normal-to-increased platelet counts with micromegakaryocytes [1, 17, 29]. Notably, $\operatorname{del}(5 q)$ may exist as an isolated cytogenetic lesion; however, it is more commonly seen as a part of complex karyotypes among TP53-mutated cases $[17,23,30]$.

As another example, SF3B1 mutations are strongly associated with increased bone marrow (BM) RS [1] and generally predict a favorable prognosis $[17,31,32]$. Of note, the $S F 3 B 1$ mutation, which generally predicts a favorable prognosis, is found in the majority of cases with MECOM (also called EVI1, at 3q26.2)-involved rearrangements, which are uniformly associated with very poor clinical outcomes $[5,17$, 33, 34].

Recently, the International Working Group for the Prognosis of MDS proposed SF3B1-mutant MDS as a distinct entity, mainly characterized by ineffective erythropoiesis, relatively good prognosis, and potential response of anemia response to luspatercept treatment (Table 4). In the proposal, RS are not required for the diagnosis of SF3B1-mutant MDS and some cytogenetic abnormalities are excluded. These abnormalities include $\operatorname{del}(5 q)$, monosomy $7, \operatorname{inv}(3)$ or abnormal $3 q 26$ (including $M E C O M$ ), and complex karyotype $(\geq 3)$ [6].

SF3B1 mutations have been reported in approximately $20 \%$ of patients with the MDS with isolated $\operatorname{del}(5 q)$, asso- 
Table 3. Gene mutation profiles for MDS/MPNs, MDS, and MPN [modified from 5, 27, 28].

\begin{tabular}{|c|c|c|c|c|c|c|c|c|}
\hline Functional class & Gene & CMML & JMML & $\mathrm{aCML}$ & MDS/MPN-RS-T & MDS/MPN-U & MDS & MPN \\
\hline \multirow{6}{*}{$\begin{array}{l}\text { Epigenetic } \\
\text { regulation }\end{array}$} & $T E T 2^{a)}$ & $50-60 \%$ & 0 & $20-40 \%$ & $10-25 \%$ & $20-25 \%$ & $20-30 \%$ & $10-20 \%$ \\
\hline & $D N M T 3 A^{\mathrm{a})}$ & $<5 \%$ & Rare & $\sim 5 \%$ & $\sim 15 \%$ & $5-10 \%$ & \multirow{2}{*}{$\begin{array}{l}\sim 10 \% \\
15-20 \%\end{array}$} & 5-10\% \\
\hline & $A S X L 1^{a)}$ & $40-45 \%$ & $\sim 5 \%$ & $\sim 30 \%$ & $15-30 \%$ & $30-50 \%$ & & $\begin{array}{l}\text { PMF 25\%, } \\
\text { ET/PV 1-3\% }\end{array}$ \\
\hline & $E Z H 2$ & $5-10 \%$ & $<5 \%$ & $\sim 20 \%$ & $\sim 5 \%$ & $\sim 15 \%$ & $5-10 \%$ & PMF 5-10\% \\
\hline & $I D H 1$ & $<5 \%$ & 0 & $<5 \%$ & & $<5 \%$ & $\sim 5 \%(I D H 1 / 2)$ & $1-3 \%$ \\
\hline & $I D H 2$ & $\sim 5 \%$ & 0 & $<5 \%$ & $<5 \%$ & $<5 \%$ & $\sim 5 \%(I D H 1 / 2)$ & $1-3 \%$ \\
\hline \multirow[t]{4}{*}{ RNA splicing } & $S R S F 2^{a)}$ & $45-50 \%$ & 0 & $30-40 \%$ & $5-10 \%$ & $\sim 25 \%$ & $\sim 15 \%$ & $\begin{array}{l}\text { PMF } 10-15 \%, \\
\text { ET }<2 \%\end{array}$ \\
\hline & $S F 3 B 1^{a)}$ & $\sim 5 \%$ & & $5-10 \%$ & $80-90 \%$ & $10-15 \%$ & $20-30 \%$ & $\mathrm{ET}<3 \%$ \\
\hline & $U 2 A F \mathcal{T}^{\mathrm{a})}$ & $5-10 \%$ & & $5-10 \%$ & $\sim 5 \%$ & $10-15 \%$ & 5-10\% & PMF 10-15\% \\
\hline & ZRSR2 & $5-10 \%$ & $<5 \%$ & $<5 \%$ & $<5 \%$ & $5-10 \%$ & $5-10 \%$ & \\
\hline \multirow[t]{10}{*}{ Cell signaling } & $N / K R A S$ & $20-30 \%$ & $25-35 \%$ & $25-35 \%$ & Rare & $10-15 \%$ & $\sim 5 \%(N R A S)$ & NRAS: PMF Rare \\
\hline & $J A K 2$ & $5-10 \%$ & 0 & $\sim 5 \%$ & $\sim 50 \%$ & $\sim 25 \%$ & & $\begin{array}{l}\text { PV 95\%, } \\
\text { PMF and ET 50-60\% }\end{array}$ \\
\hline & $J A K 3$ & & $5-15 \%$ & & & & & \\
\hline & $C B L^{\mathrm{a})}$ & $10-20 \%$ & $10-15 \%$ & $5-10 \%$ & $<5 \%$ & $\sim 5 \%$ & $\sim 5 \%$ & PMF 4\% \\
\hline & PTPN11 & $<5 \%$ & $35-45 \%$ & $<5 \%$ & & $<5 \%$ & & \\
\hline & NF1 & Rare & $10-15 \%$ & Rare & & & & PMF Rare \\
\hline & $C A L R$ & Rare & & & $<5 \%$ & $\sim 5 \%$ & & $\begin{array}{l}\text { PMF } 25-30 \% \text {, } \\
\text { ET } 20-25 \%\end{array}$ \\
\hline & $M P L$ & & & & $<5 \%$ & $\sim 5 \%$ & & $\begin{array}{l}\text { ET 2-3\%, } \\
\text { PMF 3-5\% }\end{array}$ \\
\hline & CSF3R & $<5 \%$ & & $5-10 \%$ & Rare & $<5 \%$ & & \\
\hline & FLT3 & $<5 \%$ & & $<5 \%$ & & $<5 \%$ & & $<3 \%$ \\
\hline \multirow[t]{5}{*}{ Transcription } & $R U N X 1$ & $10-20 \%$ & $<5 \%$ & $10-20 \%$ & $<5 \%$ & $5-10 \%$ & $\sim 10 \%$ & $<3 \%$ (sAML 10\%) \\
\hline & CEBPA & $<5 \%$ & & $4 \%$ & & $<5 \%$ & & \\
\hline & ETV6 & $<5 \%$ & & & $<5 \%$ & $<5 \%$ & & $<3 \%$ \\
\hline & TP5 $3^{a)}$ & Rare & & Rare & Rare & 8-9\% & $5-10 \%$ & $<5 \%$ (sAML 20\%) \\
\hline & $W T 1$ & Rare & & & & & & \\
\hline $\begin{array}{l}\text { Cohesin } \\
\text { complex }\end{array}$ & STAG2 & $<10 \%$ & & & & $5-10 \%$ & $5-7 \%$ & \\
\hline \multirow[t]{3}{*}{ Others } & ETNK1 & $<5 \%$ & & $\sim 8 \%$ & Rare & $<5 \%$ & & \\
\hline & SETBP1 & $5-10 \%$ & $5-15 \%$ & $25-40 \%$ & $\sim 10 \%$ & $10-15 \%$ & & \\
\hline & NPM1 & $<5 \%$ & & Rare & 0 & $<5 \%$ & & \\
\hline
\end{tabular}

${ }^{\text {a) }}$ These genes are also reported to be mutated in clonal hematopoietic cells in a subset of healthy individuals (clonal hematopoiesis of indeterminate potential).

Abbreviations: $\mathrm{aCML}$, atypical chronic myeloid leukemia; CMML, chronic myelomonocytic leukemia; $\mathrm{ET}$, essential thrombocythemia; JMML, juvenile myelomonocytic leukemia; MDS, myelodysplastic syndrome; MDS/MPN, myelodysplastic/myeloproliferative neoplasm; MDS/MPN-RS-T, MDS/MPN with ring sideroblasts and thrombocytosis; MDS/MPN-U, MDS/MPN unclassifiable; MPN, myeloproliferative neoplasm; PMF, primary myelofibrosis; $\mathrm{PV}$, polycythemia vera; $\mathrm{SAML}$, secondary acute myeloid leukemia.

Unknown

$<10 \%$

$10-20 \%$

$20-30 \%$

$30-50 \%$

$>50 \%$

ciated with a variable proportion of $\mathrm{RS}[6,12,25,26,32]$. These cases are classified within the category of MDS with isolated del(5q) according to the 2016 WHO criteria (Table 1) $[5,6]$. Myeloid neoplasms with concomitant $J A K 2$ mutation and $\operatorname{del}(5 q)$ may show overlapping myelodysplastic and myeloproliferative features [5, 35-39]; however, these mutations do not appear to alter the disease phenotype [5]. Despite insufficient data, such cases could benefit from a combined therapeutic approach with lenalidomide and a JAK2 inhibitor $[35,39,40]$. In contrast to generally favorable prognoses in SF3B1-mutated cases, patients with other splicing factor mutations, including mutations in $U 2 A F 1$ and SRSF2 genes, display poor overall survival [17, 41-44].
TP53 mutations account for approximately one-fourth of the high-risk MDS cases and also comprise approximately $10 \%$ of primary AML and $50 \%$ of therapy-related MDS/AML cases $[17,45,46]$. Regardless of their clinical or pathological diagnosis, patients with TP53-mutated myeloid neoplasms uniformly show a poor prognosis [23, 47].

Despite the large number of driver mutations that have been newly detected with advanced genomics-based studies, the functional roles of these driver mutations in MDS pathogenesis remain to be elucidated [17].

\section{Myelodysplastic/myeloproliferative neoplasms}

Myelodysplastic/myeloproliferative neoplasms are a heter- 
Table 4. Proposed diagnostic criteria for the myelodysplastic syndrome (MDS) with mutated SF3B1 [6].

Cytopenia defined by standard hematologic values

Somatic SF3B1 mutation

Isolated erythroid or multilineage dysplasia ${ }^{\text {a) }}$

Bone marrow blasts $<5 \%$ and peripheral blood blasts $<1 \%$

WHO criteria for MDS with isolated del(5q), MDS/MPN-RS-T or other MDS/MPNs, and primary myelofibrosis or other MPNs are not met

Normal karyotype or any cytogenetic abnormality other than del(5q); monosomy 7 ; inv(3) or abnormal 3q26, complex $(\geq 3)$

Any additional somatically mutated gene other than $R U N X 1$ and/or $E Z H 2^{\text {b) }}$

${ }^{a)} \mathrm{RS}$ are not required for the diagnosis. ${ }^{\text {b) }}$ Additional JAK2N617F, CALR, or MPL mutations strongly support the diagnosis of MDS/MPN-RS-T.

Table 5. Diagnostic criteria for chronic myelomonocytic leukemia (CMML) [5, 39].

1. Persistent peripheral blood monocytosis $\left(\geq 1 \times 10^{9} / \mathrm{L}\right)$ with monocytes accounting for $\geq 10 \%$ of the leukocytes

2. WHO criteria for BCR-ABL1-positive chronic myeloid leukemia, primary myelofibrosis, polycythemia vera, and essential thrombocythemia ${ }^{\text {a) }}$ are not met

3. No rearrangement of PDGFRA, PDGFRB or FGFR1 and no PCM1-JAK2 (which should be specifically excluded in cases with eosinophilia)

4. Blasts ${ }^{\text {b) }}$ constitute $<20 \%$ of the cells in the peripheral blood and bone marrow

5. Dysplasia involving $\geq 1$ myeloid lineages or

If myelodysplasia is absent or minimal, criteria 1-4 are met and:

- An acquired, clonal cytogenetic or molecular genetic abnormality is present in hematopoietic cells ${ }^{\mathrm{c})}$ or

- Monocytosis has persisted for $\geq 3$ months and all other causes of monocytosis (e.g., malignancy, infection, and inflammation) have been excluded.

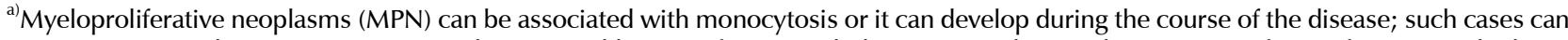
mimic CMML. In these rare instances, a documented history of MPN excludes CMML, whereas the presence of MPN features in the bone

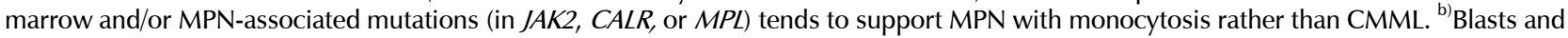
blast equivalents include myeloblasts, monoblasts, and promonocytes. Promonocytes are monocytic precursors with abundant light-grey or slightly basophilic cytoplasm with a few scattered fine lilac-colored granules, finely distributed stippled nuclear chromatin, variably prominent nucleoli, and delicate nuclear folding or creasing. Abnormal monocytes, which can be present in both the peripheral blood and the bone marrow are excluded from the blast count. Abnormal monocytes show convoluted nuclei as mature monocytes, but less clumped chromatin, minute nucleoli, and more basophilic cytoplasm. ${ }^{~ C)}$ In the appropriate clinical context, mutations in genes often associated with CMML (e.g., TET2, SRSF2, ASXL1 and SETBP1) support the diagnosis. However, some of these mutations can be age-related or present in other neoplasms; therefore, these genetic findings must be interpreted with caution.

ogeneous group of clonal hematopoietic neoplasms with features common to both MDS and MPN [1, 2]. These neoplasms include CMML, atypical chronic myeloid leukemia (aCML), juvenile myelomonocytic leukemia (JMML), MDS/MPN with RS and thrombocytosis (MDS/MPN-RS-T), and MDS/MPN, unclassifiable (MDS/MPN-U) [1].

The diagnosis and classification of these "hybrid myeloid neoplasms" can be challenging despite applying the relevant diagnostic criteria. Some patients with MDS may initially show thrombocytosis, whereas some MPN cases may have significant cytopenia(s). In addition, dysplastic features and monocytosis can be seen in MPNs, further complicating the differential diagnosis, particularly when the initial diagnostic material is not available for review [48].

Chronic myelomonocytic leukemia: CMML is characterized by a pathologic myeloproliferation of granulocytic and monocytic cells with cytopenia and myelodysplasia [39, 49]. CMML is the most common type of MDS/MPN overlap syndrome $[49,50]$. In the French-American-British classification, CMML was classified as one of the 5 subtypes of MDS. It was placed in a newly created disease group, the MDS/MPN overlap category in the 2001 WHO classification system of myeloid neoplasms $[49,51]$. The diagnostic criteria for CMML are summarized in Table 5 [5].

CMML has been classified into CMML-1 and CMML-2 based on the circulating and BM blast count, a prognostic factor that had been consistently shown to be associated with poor survival $[49,52,53]$. The $2016 \mathrm{WHO}$ classification system further expanded these groups into CMML-0 [peripheral blood (PB) <2\%, BM <5\%], CMML-1 (PB 2-4\%; BM 5-9\%) and CMML-2 (PB 5-19\%, BM 10-19\%, or presence of Auer rods). This categorization identifies distinct prognostic groups with a median survival of 31,19 , and 13 months, respectively $(P<0.001)[1,49,53]$. However, the 3 -tiered blast-based subgroups are somewhat controversial and it was noted that the newly proposed CMML- 0 and CMML- 1 categories were similar in terms of the CMML-specific Prognostic Scoring System (CPSS) [54] risk profile, cytogenetic risk groups, and mutation profiles [48]. In addition, the low concordance rate for blast enumeration was reported in CMML $[48,55,56]$ and it was suggested that adding the CMML-0 subcategory does not have clear prognostic benefits [48, 57].

Moreover, CMML can be subclassified into a "myelodysplastic" variant ("MD-CMML"), defined by white blood cell (WBC) count of $<13 \times 10^{9} / \mathrm{L}$, and a "myeloproliferative" variant ("MP-CMML"), with WBC count of $\geq 13 \times 10^{9} / \mathrm{L}[39$, 
$49,53,54,58,59]$. The prognostic significance of such a classification has not been consistently reported; however, molecular data has demonstrated significant differences among MP-CMML (RAS/MAPK enriched) and MD-CMML $[1,49]$. Notably, inconsistencies in categorizing patients into MP and MD-CMML prognostic groups based on a single WBC count at diagnosis can occur because of fluctuations in the WBC count in the early clinical course of CMML $[49,60]$.

"Oligomonocytic" CMML, which often represents a prodromal phase of the disease, is defined by relative monocytosis $(\geq 10 \%$ ), with an absolute monocyte count of 0.5 $0.9 \times 10^{9} / \mathrm{L}$, in the presence of BM findings consistent with CMML and molecular results supportive of it [39, 61-63]. Patients with oligomonocytic CMML often display a similar molecular profile to that of classic CMML, with many cases progressing to frank disease [27, 63].

$B C R-A B L 1$-positive CML can present with monocytosis, especially with the presence of the p190 $B C R-A B L 1$ fusion transcript [5, 39]. Monocytosis in aCML is usually absent or minimal, and when present, the monocytes should account for $<10 \%$ of PB leukocytes [39]. Rarely, MPN associated with monocytosis may mimic CMML; additionally, the presence of MPN clonal markers, such as $J A K 2, M P L$, or $C A L R$, and BM evidence of MPN favors a diagnosis of MPN over CMML [1, 49].

Conventional metaphase karyotyping shows chromosomal abnormalities in approximately $30 \%$ of the patients with CMML, and common karyotypic abnormalities include +8 (23\%) and del 7/-7q (14\%), which are non-specific and not diagnostic of CMML $[49,64]$. With the use of high-resolution SNP array-based karyotyping, up to $60 \%$ of the patients have been shown to have chromosomal aberrations $[49,65]$.

At least one mutation is detected in $86-98 \%$ of CMML cases [49]. While no mutation defines CMML, it could aid in diagnosis [27, 49]. The most frequent point mutations seen in CMML include TET2 (50-60\%), SRSF2 (45-50\%), and $A S X L 1$ (40-45\%), which are the hallmark molecular findings of CMML, and the combination of SRSF2 and TET2 mutations is particularly suggestive of CMML (Table 3) [27, 39, 49]. TP53 mutations are quite rare in CMML (only 1\% of cases) [27, 66, 67].

TET2 mutation has been shown to be an early event in CMML pathogenesis, with the early clonal dominance of TET2 mutated cells being responsible for monocytic skewing, resulting in the CMML phenotype [27,68]. Up to $40 \%$ of the patients have mutations in cell signaling pathways, particularly the RAS pathway genes (NRAS, KRAS, CBL) and $J A K 2$, which are more common in the MP-CMML subtype $[58,69]$. RUNX1 mutations are noted in $10-20 \%$ of patients, with additional mutations noted in other splicing complex genes (SF3B1, ZRSR2, U2AF1); moreover, mutations in genes associated with epigenetic regulation (DNMT3A, EZH2) have been observed at frequencies of $<10 \%$ [27, 70, 71].

Atypical chronic myeloid leukemia, $B C R-A B L 1$ negative: Atypical chronic myeloid leukemia, $B C R-A B L 1$ negative is a leukemic disorder that predominantly affects the neutrophilic lineage; it is associated with neutrophilic leukocytosis and circulating immature granulocytic precursors constituting $\geq 10 \%$ of all leukocytes [5, 39]. The diagnostic criteria for aCML are summarized in Table 6 [5].

Prominent dysgranulopoiesis and other dysplastic features seen on $\mathrm{BM}$ aspirate are important features of aCML that distinguish it from CML, in addition to the lack of $B C R-A B L 1$ translocation $[1,49,51]$. The mature neutrophils often display hyposegmented and/or bizarrely segmented nuclei, although in some cases, the dysplastic features are relatively subtle. The so-called "syndrome of abnormal chromatin clumping" is considered to be a variant of aCML. In these cases, circulating neutrophils exhibit a characteristic exaggerated clumping of nuclear chromatin, producing darker nuclei [39, 72, 73]. On metaphase cytogenetics of aCML patients, +8 and +21 are frequently found, with +13 , del(20q) and $i(17 q)$ being less common [49, 74, 75].

In the 2016 WHO classification, there is an emphasis on identifying the recurrent molecular markers seen in

Table 6. Diagnostic criteria for atypical chronic myeloid leukemia, BCR-ABL1-negative (aCML) [5].

\footnotetext{
- Peripheral blood leukocytosis $\geq 13 \times 10^{9} / \mathrm{L}$, due to increased numbers of neutrophils and their precursors (i.e., promyelocytes, myelocytes, and metamyelocytes), with neutrophil precursors constituting $\geq 10 \%$ of the leukocytes

- Dysgranulopoiesis, which may include abnormal chromatin clumping

- No or minimal absolute basophilia; basophils constitute $<2 \%$ of the peripheral blood leukocytes

- No or minimal absolute monocytosis; monocytes constitute $<10 \%$ of the peripheral blood leukocytes

- Hypercellular bone marrow with granulocytic proliferation and granulocytic dysplasia, with or without dysplasia in the erythroid and megakaryocytic lineages

$-<20 \%$ blasts in the blood and bone marrow

- No evidence of PDGFRA, PDGFRB, or FGFR1 rearrangement, or of PCM1-JAK2

- The WHO criteria for BCR-ABL1-positive chronic myeloid leukemia, primary myelofibrosis, polycythemia vera, or essential thrombocythemia) are not met.
}

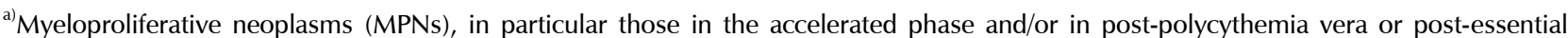
thrombocythemia myelofibrosis, if neutrophilic, may simulate aCML. A history of MPN, the presence of MPN features in the bone marrow, and/or MPN-associated mutations (in JAK2, CALR, or MPL) tend to exclude the diagnosis of aCML; conversely, the diagnosis is supported by the presence of SETBP1 and/or ETNK1 mutations. CSF3R mutation is uncommon and, if detected, should prompt careful morphological review to exclude an alternative diagnosis of chronic neutrophilic leukemia or another myeloid neoplasm. 
aCML, i.e., SETBP1 (25-40\%) and ETNK1 (approximately $8 \%$ ) mutations (Table 3) [27, 39, 49, 76-80]. In addition, mutations commonly observed in other MDS/MPNs, including ASXL1, EZH2, TET2, SRSF2, and N/KRAS, are observed in $\geq 20 \%$ of aCML cases, while others are seen at lower frequencies [77, 81-83]. SETBP1 mutations were shown to correlate with monosomy 7, isochromosome i(17)(q10), $A S X L 1$, and $C B L$ mutations, and to be mutually exclusive of JAK2 and TET2 mutations [27, 82]. Studies on CSF3R mutations has demonstrated its high prevalence (80-90\%) in chronic neutrophilic leukemia and a relatively low frequency $(<1$ to $10 \%$ ) in aCML, with a rare incidence in other myeloid disorders [27, 49, 78, 84, 85]. Less frequently, MPN-like mutations in JAK2 (approximately 5\%) and complete lack of $M P L$ or $C A L R$ mutations have been shown in aCML [27, 49, 86].

Juvenile myelomonocytic leukemia: JMML is a clonal hematopoietic neoplasm of childhood, with a median age at presentation of 2 years [5]. As the childhood counterpart of CMML, JMML shares many clinical and molecular features with CMML, as patients present with leukocytosis and monocytosis, the latter being generally $\geq 1 \times 10^{9} / \mathrm{L}$. The diagnostic criteria for JMML are summarized in Table 7 [5, 87]. JMML is an aggressive disease with progressive BM failure and short survival [39]. Cytogenetic abnormalities are seen in $30-35 \%$ of patients and sole monosomy 7 is seen in $25 \%$ of patients [88, 89].

Although its morphologic features are similar to CMML, JMML differs due to its specific and unique pathogenic background as up to $90 \%$ of patients harbor either somatic or germline mutations in one of the RAS-MAPK pathway genes (Table 3) [27, 39, 90, 91]. The most common mutations in patients with JMML occur in PTPN11, N/KRAS, NF1, and $C B L$ genes [27, 90-97]. Activating somatic $R R A S$ muta- tions have been shown in few of the cases that are negative for all 5 common mutations [90, 95, 98]. Congenital predisposition is observed and includes patients with a germline NF1 mutation (characteristic of neurofibromatosis type 1), PTPN11 mutation (observed in half of the patients with Noonan syndrome), and a germline syndrome associated with mutations in $C B L[27,92,99]$. The mutations observed in other MDS/MPNs, such as TET2, SRSF2, and JAK2, are not seen, and $A S X L 1$ mutations are rarely reported [27, 94-96, 98, 100]. However, secondary mutations in SETBP1 and JAK3 are observed in up to $15 \%$ of patients with JMML [27, 93, 96]. MP-CMML largely occurs due to RAS pathway mutations that occur in the context of age-related clonal hematopoiesis (TET2, SRSF2, ASXL1), while JMML is a bona fide RASopathy, with additional somatic mutations, including in the epigenetic regulator genes, resulting in disease progression [88].

The differential diagnosis of the JMML phenotype includes rare myeloproliferative malignancies with receptor tyrosine kinase translocations [90]. In RAS pathway mutation-negative cases, disorders with a clinical and hematological picture mimicking that of JMML, such as infection, WiskottAldrich syndrome, and malignant infantile osteopetrosis, must be excluded [5, 101-103].

MDS/MPN with ring sideroblasts and thrombocytosis: "Refractory anemia with ringed sideroblasts associated with marked thrombocytosis (RARS-T)" was included as a provisional entity in 2001 WHO classification of myeloid neoplasm, with the updated 2016 classification accepting it as a distinct entity; it is now referred to as "MDS/MPN-RS-T" $[1,49]$. The concomitant presence of mutations in $S F 3 B 1$, an MDS-type mutation and one of the MPN mutations, i.e., $J A K 2, M P L$, and $C A L R$, reinforces its categorization into this disease category $[1,49]$. The diagnostic criteria for

Table 7. Diagnostic criteria for juvenile myelomonocytic leukemia (JMML) [5, 87].

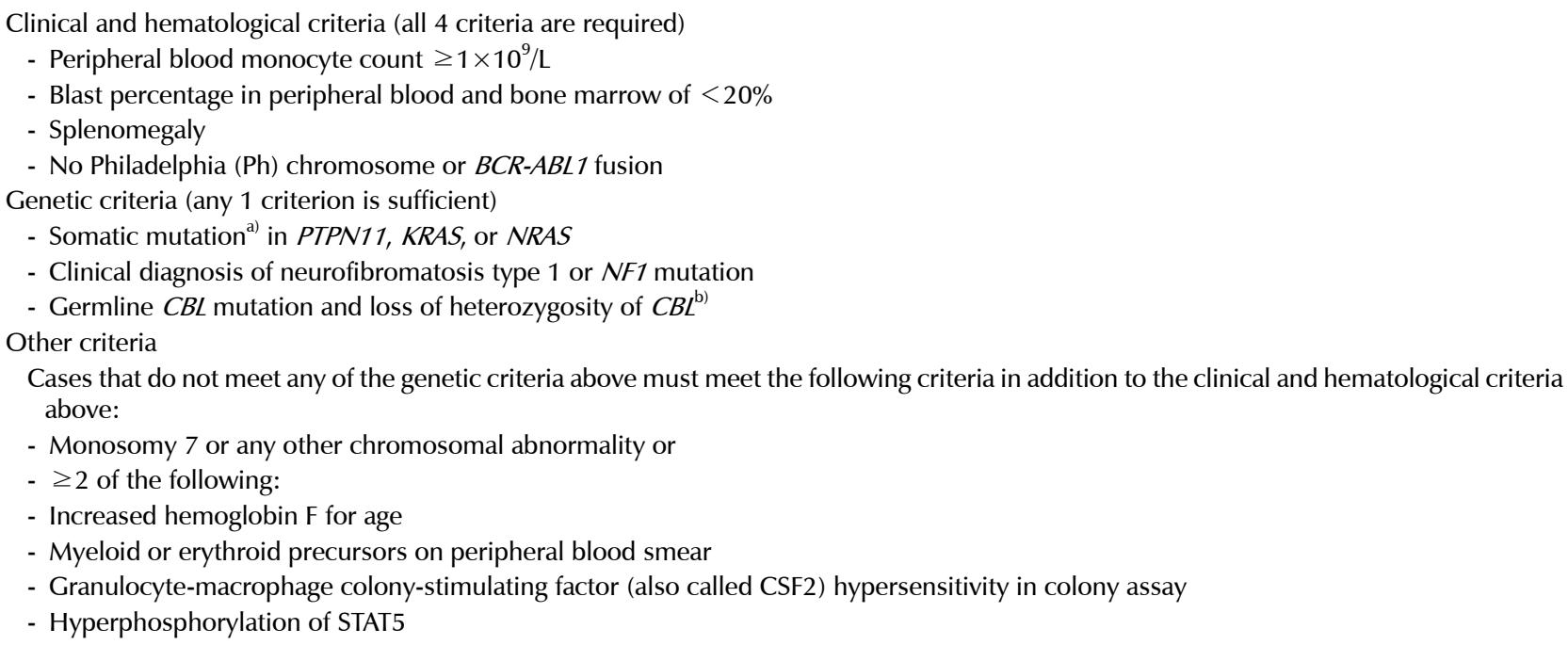

a) If a mutation is found in PTPN11, KRAS, or NRAS, it is essential to consider that it might be a germline mutation and the diagnosis of transient

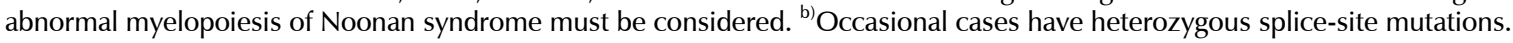


MDS/MPN-RS-T are summarized in Table 8 [5].

Macrocytic or normocytic anemia and thrombocytosis $\left(\geq 450 \times 10^{9} / \mathrm{L}\right)$ are present and BM shows dyserythropoiesis ("MDS-like" feature) and large atypical megakaryocytes ("MPN-like" feature) similar to those observed in $B C R-A B L 1-$ negative MPN [1, 39, 49]. RS represent $\geq 15 \%$ of the nucleated erythroid cells. This finding is also observed in MDS-RS, which is a subtype of MDS and lacks thrombocytosis and megakaryocytic hyperplasia [39]. Large, hyperlobulated megakaryocytes and BM fibrosis are findings similar to MPN, such as essential thrombocythemia (ET) and primary myelofibrosis (PMF). However, ET generally shows no dysplasia and normocellular marrow for age [39]. MDS/MPN-RS-T shows a poorer prognosis than both MDS-RS and ET, and differential diagnoses are clinically important [39, 76].

The majority of the patients with MDS/MPN-RS-T have a normal karyotype (82.6\%), while molecular aberrations are seen in $>95 \%$ of the patients [49]. MDS/MPN-RS-T shows a molecular profile that combines the genetic features of MDS and MPN (Table 3) [27]. The mutations in SF3B1 have been shown to be a hallmark of MDS-RS, occurring in $>80 \%$ of cases, and the mutations have been demonstrated in a similar proportion of patients with MDS/MPN-RS-T $[12,27,32]$. As the second most common molecular finding and accounting for the proliferative features of the disease, $J A K 2$ mutations are observed in over $50 \%$ of patients, and somatic mutations in ASXL1, TET2, DNMT3A, and SETBP1 genes occur in about $10-30 \%$ of patients, while $M P L$ and
CALR mutations are observed in $<5 \%$ of patients [27, 32, 104-108]. SF3B1 is concomitantly mutated with JAK2 in $50 \%$ of the cases, while cases with wild type $S F 3 B 1$ tend to harbor $A S X L 1$ and $J A K 2$ mutations, and are negatively associated with SRSF2 and U2AF1 mutations [49, 105]. Although studies for these mutations are not required for the diagnosis of MDS/MPN-RS-T, the detection of these mutations supports the diagnosis and has prognostic implications as JAK2 mutated cases appear to have a better prognosis than the triple negative cases [5, 32, 39, 109, 110].

Spliceosome mutations are thought to represent the founder mutation in the MDS/MPN-RS-T, with nearly all SF3B1 wild-type cases harboring a mutation in an alternative splicing gene $[27,105]$. The allelic frequency of $S F 3 B 1$ is typically the highest among all identified mutations and the acquisition of an MPN-associated mutation (JAK2, CALR, or MPL) has been suggested to lead to the evolution of MDS-RS to MDS/MPN-RS-T [32, 105, 110].

MDS/MPN, unclassifiable: As the least characterized disease of the group, MDS/MPN-U includes cases of myeloid neoplasms showing both myeloproliferative and myelodysplastic features at the time of the initial presentation, but which do not entirely fulfill the diagnostic criteria for any specific subtype of MDS/MPN, MDS, or MPN [5, 27, 39]. Cases of MDS/MPN-U are more heterogeneous, not forming a unique subset of diseases; however, similar to other entities, these cases must present with cytosis and cytopenia that is not attributable to a known antecedent history of MDS or MPN

Table 8. Diagnostic criteria for myelodysplastic/myeloproliferative neoplasm with ring sideroblasts and thrombocytosis (MDS/MPN-RS-T) [5].

- Anemia associated with erythroid-lineage dysplasia, with or without multilineage dysplasia;

$\geq 15 \%$ ring sideroblasts ${ }^{\mathrm{a}}{ }^{2},<1 \%$ blasts in the peripheral blood, and $<5 \%$ blasts in the bone marrow

- Persistent thrombocytosis, with platelet count $\geq 450 \times 10^{9} / \mathrm{L}$

- SF3B1 mutation or, in the absence of $S F 3 B 1$ mutation, no history of recent cytotoxic or growth factor therapy that could explain the myelodysplastic/myeloproliferative features ${ }^{\text {b) }}$

- No BCR-ABL1 fusion; no rearrangement of PDGFRA, PDGFRB or FGFR1; no PCM1-JAK2 and no $\mathrm{t}(3 ; 3)(\mathrm{q} 21.3 ; \mathrm{q} 26.2)$, inv(3)(q21.3q26.2), or $\operatorname{del}(5 \mathrm{q})^{\mathrm{c}}$

- No history of myeloproliferative neoplasm, myelodysplastic syndrome (except myelodysplastic syndrome with ring sideroblasts), or other myelodysplastic/myeloproliferative neoplasm

a) $\geq 15 \%$ ring sideroblasts is a required criterion even if $S F 3 B 1$ mutation is detected. ${ }^{\text {b) }}$ The diagnosis of myelodysplastic/myeloproliferative neoplasm with ring sideroblasts and thrombocytosis is strongly supported by the presence of SF3B1 mutation together with a JAK2 V617F, $C A L R$, or MPL mutation. ${ }^{c}$ In a case that otherwise meets the diagnostic criteria for myelodysplastic syndrome with isolated del(5q).

Table 9. Diagnostic criteria for myelodysplastic/myeloproliferative neoplasm, unclassifiable (MDS/MPN-U) [5].

Myeloid neoplasm with mixed myeloproliferative and myelodysplastic features at onset, not meeting the WHO criteria for any other myelodysplastic/myeloproliferative neoplasm, myelodysplastic syndrome, or myeloproliferative neoplasm - $<20 \%$ blasts in the peripheral blood and bone marrow

- Clinical and morphological features of one of the categories of myelodysplastic syndrome ${ }^{\text {a) }}$

- Clinical and morphological myeloproliferative features manifesting as a platelet count of $\geq 450 \times 10^{9} / \mathrm{L}$ associated with bone marrow megakaryocytic proliferation and/or a white blood cell count of $\geq 13 \times 10^{9} / \mathrm{L}^{\mathrm{a})}$

- No history of recent cytotoxic or growth factor therapy that could explain the myelodysplastic/myeloproliferative features

- No PDGFRA, PDGFRB, or FGFR1 rearrangement and no PCM1-JAK2

${ }^{a}$ Cases that meet the criteria for myelodysplastic syndrome with isolated del $(5 q)$ are excluded irrespective of the presence of thrombocytosis or leukocytosis. 
[48]. In the 2016 WHO classification of myeloid neoplasms, MDS/MPN-U continues to be a provisional entity $[1,49]$. The diagnostic criteria for MDS/MPN-U are summarized in Table 9 [5].

The differential diagnosis between MDS/MPN-U and aCML can be challenging, as MDS/MPN-U can show overlapping features with aCML. This differential diagnosis has relevant prognostic implications, since aCML shows poorer overall survival and shorter acute leukemia free survival than MDS/MPN-U $[39,86]$. On PB, aCML generally shows higher WBC counts than those observed in MDS/MPN-U. The platelet count can be increased in MDS/MPN-U, while thrombocytopenia is more common in aCML.

There is no recurrent cytogenetic feature of MDS/MPN-U, with the majority (49\%) of the patients having diploid karyotype, and +8 is seen in $15 \%$ of patients $[49,50,111,112]$.

There are no molecular genetic findings specific for MDS/MPN-U (Table 3) [5, 27]. The ASXL1 mutation has been identified as the most frequent molecular abnormality, occurring in $29-56 \%$ of patients with MDS/MPN-U [27, 113-115]. Mutations in TET2, SRSF2, and JAK2 are seen in approximately $25 \%$ of the patients, with mutations in other splicing genes-SETBP1,EZH2, and N/KRAS - each seen in approximately $10-15 \%$ of the patients $[27,80,86$, 111, 113-115]. TP53 mutations have been reported in 8-9\% of cases, higher than what is reported in other MDS/MPNs, while a variety of other genes recurrently mutated across myeloid malignancies are seen at low frequencies [27, 114, 115]. The common driver mutations of MPN (i.e., JAK2, $C A L R, M P L)$ tend to exclude the diagnosis since they may be seen in MPN cases or in the disease progression. However, in cases without a previous history of MPN they might be useful to confirm the diagnosis $[39,108,109,116]$.

\section{Hypoplastic MDS and aplastic anemia}

Hypoplastic MDS represents approximately $10-15 \%$ of patients, and defined by a BM cellularity $<25 \%$ on trephine biopsy or by an inappropriately reduced cellularity for their age in younger patients $[117,118]$; however, their diagnosis is still an object of debate and has not been clearly established as a specific subtype in the 2016 WHO classification [117].

Hypocellularity in MDS may lead to difficulties in the differential diagnosis with AA [5]. Dysmegakaryopoiesis, dysgranulopoiesis, and the identification of sideroblasts (on BM aspirate) or clusters of blasts (identified by CD34 immunostaining of BM biopsy sections) are helpful in this distinction [5, 117, 119]. Mild, isolated dyserythropoiesis is very common in AA but cannot be used as a distinctive feature [117]. In younger patients, inherited BM failure syndromes should be considered and it is important to investigate the family history, extramedullary manifestations, and specific genes associated with BM failure with germline predisposition according to the 2016 WHO classification [1, 117].

Hypoplastic MDS is characterized by BM hypoplasia, a low rate of progression to acute leukemia, and a poor response to conventional MDS therapies $[117,120]$. The clinical and laboratory markers situate hMDS in the middle of the clinical spectrum between normo/hypercellular MDS and AA (Table 10) [117].

The genomic landscape of hMDS resulted in-between AA and non-hMDS in terms of the number of somatic mutations (AA $<$ hMDS $<$ non-hMDS), variant allele frequency (AA $<$ hMDS $<$ non-hMDS), and involved genes (Table 10) [117]. The largest study illustrated that $38 \%$ of patients with h-MDS

Table 10. Semiquantitative comparison of laboratory and genetic features among hMDS, AA, and normo/hypercellular MDS (modified from 117).

\begin{tabular}{|c|c|c|c|}
\hline Properties & Normo/hypercellular MDS & hMDS & AA \\
\hline \multicolumn{4}{|l|}{ Laboratory features } \\
\hline Cytopenia and macrocytosis & + & ++ & ++ \\
\hline $\mathrm{LDH}$ & $+/-$ & + & ++ \\
\hline BM blasts & $=/+$ & - & -- \\
\hline \multicolumn{4}{|l|}{ Associated conditions } \\
\hline PNH clone & +1 & + & ++ \\
\hline LGL clone & + & ++ & $+/-$ \\
\hline Extrahematologic autoimmunity & - & ++ & $+/-$ \\
\hline Cytogenetic abnormalities & ++ & $+/-$ & Rare \\
\hline \multicolumn{4}{|l|}{ Somatic mutations } \\
\hline Splicing: SF3B1, SRSF2, U2AF1, ZRSR2 & +++ & + & $+/-$ \\
\hline DNA methylation: DNMT3A, TET2, IDH1, IDH2 & ++ & + & $+/-$ \\
\hline Chromatin modification: $A S X L 1, E Z H 2, K D M 6 A$ & ++ & + & $+/-$ \\
\hline Cohesin: STAG2 & + & $+/-$ & Rare \\
\hline Tumor suppressor: TP53 & + & $+/-$ & Rare \\
\hline Signaling: $C B L, F L T 3, J A K 2, K I T, N R A S, K R A S$ & $+/-$ & $+/-$ & Rare \\
\hline Transcription: RUNX1, CEBPA, ETV6, GATA2, NPM1 & $R U N X 1=/++;$ others $=+/-$ & $+/-$ & Rare \\
\hline Pathogenic germline RTEL1 mutations & - & $+/-$ & + \\
\hline
\end{tabular}

Abbreviations: AA, aplastic anemia; BM, bone marrow; hMDS, hypoplastic myelodysplastic syndrome; LDH, lactate dehydrogenase; LGL, large granular lymphocytes; MDS, myelodysplastic syndrome; $\mathrm{PNH}$, paroxysmal nocturnal hemoglobinuria. 
harbored at least one somatic mutation, albeit with a lower number of mutations per patient when comparing h-MDS with non-hMDS $[118,121]$. In the study, SF3B1, TET2, $D N M T 3 A$, and SRSF2 mutations were the most prevalent in h-MDS [118, 121]. In addition, a significantly higher prevalence of $\mathrm{PNH}$ clones was present among the patients with h-MDS compared with non-hMDS [118, 121]. It is reported that $20 \%$ to $35 \%$ of $\mathrm{AA}$ patients have somatic mutations associated with hematologic malignancies, most characteristically in the $A S X L 1, B C O R$, and BCORL1 genes [122].

Hypoplastic MDS may have both pathogenetic mechanisms similar to that of MDS (selective growth advantage of somatically mutated clonal hematopoietic progenitor cells) and AA (immune-mediated destruction of marrow precursors) [117]. The integration of laboratory and genetic features enabled the segregation of hMDS patients into two distinct groups: one highly consistent with the profile of myeloid neoplasms and the other more closely resembling AA, with no evidence of clonal disease $[117,118]$. In summary, hMDS more likely represents a mixture of entities along a spectrum rather than a homogeneous in-between category [117].

\section{CONCLUSION}

MDS/MPNs have the characteristics of both MDS and MPN; however, their molecular characteristics usually do not show an "in-between" form, and it has been reported that they show various spectra within the group. Notably, MDS/MPN-RS-T is regarded as a "true hybrid" neoplasm in terms of both clinicopathological and molecular characteristics. Similarly, it is possible that hMDS may not be an AA-like hypocellular form of MDS but a heterogeneous group.

The advances in next-generation sequencing technology have led to the discovery of frequent mutations in MDS and overlap syndromes; however, most of the mutations are not specific for the diagnosis of these diseases. The established diagnostic criteria for these diseases based on clinical, morphologic, and laboratory features are still useful combined with the genomic data.

It is expected that a further revised classification of MDS and the overlap syndromes will focus on the roles of the mutations as therapeutic targets and prognostic indicators.

\section{Authors' Disclosures of Potential Conflicts of Interest}

No potential conflicts of interest relevant to this article were reported.

\section{REFERENCES}

1. Arber DA, Orazi A, Hasserjian R, et al. The 2016 revision to the World Health Organization classification of myeloid neoplasms and acute leukemia. Blood 2016;127:2391-405.

2. Zini G. Diagnostics and prognostication of myelodysplastic syndromes. Ann Lab Med 2017;37:465-74.

3. Hasserjian RP. Myelodysplastic syndrome updated. Pathobiology 2019;86:7-13

4. Tanaka TN, Bejar R. MDS overlap disorders and diagnostic boundaries. Blood 2019;133:1086-95.

5. Swerdlow SH, Campo E, Harris NL, et al, eds. WHO classification of tumours of haematopoietic and lymphoid tissues. 4th ed. Lyon, France: IARC, 2017.

6. Malcovati L, Stevenson K, Papaemmanuil E, et al. SF3B1-mutant MDS as a distinct disease subtype: a proposal from the International Working Group for the Prognosis of MDS. Blood 2020;136:157-70.

7. Malcovati L, Porta MG, Pascutto C, et al. Prognostic factors and life expectancy in myelodysplastic syndromes classified according to WHO criteria: a basis for clinical decision making. J Clin Oncol 2005;23:7594-603.

8. Malcovati L, Germing U, Kuendgen A, et al. Time-dependent prognostic scoring system for predicting survival and leukemic evolution in myelodysplastic syndromes. J Clin Oncol 2007; 25:3503-10.

9. Arber DA, Hasserjian RP. Reclassifying myelodysplastic syndromes: what's where in the new WHO and why. Hematology Am Soc Hematol Educ Program 2015;2015:294-8.

10. Cazzola M, Rossi M, Malcovati L; Associazione Italiana per la Ricerca sul Cancro Gruppo Italiano Malattie Mieloproliferative. Biologic and clinical significance of somatic mutations of SF3B1 in myeloid and lymphoid neoplasms. Blood 2013;121:260-9.

11. Patnaik MM, Hanson CA, Sulai NH, et al. Prognostic irrelevance of ring sideroblast percentage in World Health Organizationdefined myelodysplastic syndromes without excess blasts. Blood 2012;119:5674-7.

12. Malcovati L, Papaemmanuil E, Bowen DT, et al. Clinical significance of SF3B1 mutations in myelodysplastic syndromes and myelodysplastic/myeloproliferative neoplasms. Blood 2011;118:6239-46.

13. Bennett JM. Changes in the updated 2016: WHO classification of the myelodysplastic syndromes and related myeloid neoplasms. Clin Lymphoma Myeloma Leuk 2016;16:607-9.

14. Vardiman JW, Thiele J, Arber DA, et al. The 2008 revision of the World Health Organization (WHO) classification of myeloid neoplasms and acute leukemia: rationale and important changes. Blood 2009;114:937-51.

15. Germing U, Lauseker M, Hildebrandt B, et al. Survival, prognostic factors and rates of leukemic transformation in 381 untreated patients with MDS and del(5q): a multicenter study. Leukemia 2012;26:1286-92.

16. Mallo M, Cervera J, Schanz J, et al. Impact of adjunct cytogenetic abnormalities for prognostic stratification in patients with myelodysplastic syndrome and deletion 5q. Leukemia 2011;25: 110-20.

17. Ogawa S. Genetics of MDS. Blood 2019;133:1049-59.

18. Haase D. Cytogenetic features in myelodysplastic syndromes. Ann Hematol 2008;87:515-26.

19. Haase D, Germing U, Schanz J, et al. New insights into the prognostic impact of the karyotype in MDS and correlation with 
subtypes: evidence from a core dataset of 2124 patients. Blood 2007;110:4385-95.

20. Le Beau MM, Espinosa R 3rd, Davis EM, Eisenbart JD, Larson RA, Green ED. Cytogenetic and molecular delineation of a region of chromosome 7 commonly deleted in malignant myeloid diseases. Blood 1996;88:1930-5.

21. Jädersten M, Saft L, Smith A, et al. TP53 mutations in low-risk myelodysplastic syndromes with del(5q) predict disease progression. J Clin Oncol 2011;29:1971-9.

22. Soenen V, Preudhomme C, Roumier C, Daudignon A, Laï JL, Fenaux P. 17p deletion in acute myeloid leukemia and myelodysplastic syndrome. Analysis of breakpoints and deleted segments by fluorescence in situ. Blood 1998;91:1008-15.

23. Yoshizato T, Nannya Y, Atsuta Y, et al. Genetic abnormalities in myelodysplasia and secondary acute myeloid leukemia: impact on outcome of stem cell transplantation. Blood 2017; 129:2347-58.

24. Sato-Otsubo A, Sanada M, Ogawa S. Single-nucleotide polymorphism array karyotyping in clinical practice: where, when, and how? Semin Oncol 2012;39:13-25.

25. Haferlach T, Nagata Y, Grossmann V, et al. Landscape of genetic lesions in 944 patients with myelodysplastic syndromes. Leukemia 2014;28:241-7.

26. Papaemmanuil E, Gerstung M, Malcovati L, et al. Clinical and biological implications of driver mutations in myelodysplastic syndromes. Blood 2013;122:3616-27.

27. Hunter AM, Padron E. Molecular genetics of MDS/MPN overlap syndromes. Best Pract Res Clin Haematol 2020;33:101195.

28. Vainchenker W, Kralovics R. Genetic basis and molecular pathophysiology of classical myeloproliferative neoplasms. Blood 2017;129:667-79.

29. Van den Berghe H, Cassiman JJ, David G, Fryns JP, Michaux JL, Sokal G. Distinct haematological disorder with deletion of long arm of no. 5 chromosome. Nature 1974;251:437-8.

30. Jerez A, Gondek LP, Jankowska AM, et al. Topography, clinical, and genomic correlates of $5 q$ myeloid malignancies revisited. J Clin Oncol 2012;30:1343-9.

31. Papaemmanuil E, Cazzola M, Boultwood J, et al. Somatic SF3B1 mutation in myelodysplasia with ring sideroblasts. N Engl J Med 2011;365:1384-95.

32. Malcovati L, Karimi M, Papaemmanuil E, et al. SF3B1 mutation identifies a distinct subset of myelodysplastic syndrome with ring sideroblasts. Blood 2015;126:233-41.

33. Lavallée VP, Gendron P, Lemieux S, D’Angelo G, Hébert J, Sauvageau G. EVI1-rearranged acute myeloid leukemias are characterized by distinct molecular alterations. Blood 2015; 125:140-3.

34. Shiozawa Y, Malcovati L, Gallì A, et al. Gene expression and risk of leukemic transformation in myelodysplasia. Blood 2017;130: 2642-53.

35. Sangiorgio VFI, Geyer JT, Margolskee E, et al. Myeloid neoplasms with isolated del(5q) and JAK2 V617F mutation: a "grey zone" combination of myelodysplastic and myeloproliferative features? Haematologica 2020;105:e276-9.

36. Ingram W, Lea NC, Cervera J, et al. The JAK2 V617F mutation identifies a subgroup of MDS patients with isolated deletion $5 q$ and a proliferative bone marrow. Leukemia 2006;20:1319-21.
37. Patnaik MM, Lasho TL, Finke CM, et al. WHO-defined 'myelodysplastic syndrome with isolated $\operatorname{del}(5 q)$ ' in 88 consecutive patients: survival data, leukemic transformation rates and prevalence of JAK2, MPL and IDH mutations. Leukemia 2010;24:1283-9.

38. Meggendorfer M, Haferlach C, Kern W, Haferlach T. Molecular analysis of myelodysplastic syndrome with isolated deletion of the long arm of chromosome 5 reveals a specific spectrum of molecular mutations with prognostic impact: a study on 123 patients and 27 genes. Haematologica 2017;102:1502-10.

39. Sangiorgio VFI, Orazi A, Arber DA. Myelodysplastic/ myeloproliferative neoplasms: are morphology and immunophenotyping still relevant? Best Pract Res Clin Haematol 2020;33:101139.

40. Musto P, Simeon V, Guariglia R, et al. Myelodysplastic disorders carrying both isolated $\operatorname{del}(5 q)$ and JAK2(V617F) mutation: concise review, with focus on lenalidomide therapy. Onco Targets Ther 2014;7:1043-50.

41. Graubert TA, Shen D, Ding L, et al. Recurrent mutations in the U2AF1 splicing factor in myelodysplastic syndromes. Nat Genet 2011;44:53-7.

42. Damm F, Kosmider O, Gelsi-Boyer V, et al. Mutations affecting mRNA splicing define distinct clinical phenotypes and correlate with patient outcome in myelodysplastic syndromes. Blood 2012;119:3211-8.

43. Makishima $\mathrm{H}$, Visconte $\mathrm{V}$, Sakaguchi $\mathrm{H}$, et al. Mutations in the spliceosome machinery, a novel and ubiquitous pathway in leukemogenesis. Blood 2012;119:3203-10.

44. Thol F, Kade S, Schlarmann C, et al. Frequency and prognostic impact of mutations in SRSF2, U2AF1, and ZRSR2 in patients with myelodysplastic syndromes. Blood 2012;119:3578-84.

45. Kulasekararaj AG, Smith AE, Mian SA, et al. TP53 mutations in myelodysplastic syndrome are strongly correlated with aberrations of chromosome 5, and correlate with adverse prognosis. Br J Haematol 2013;160:660-72.

46. Wong TN, Ramsingh G, Young AL, et al. Role of TP53 mutations in the origin and evolution of therapy-related acute myeloid leukaemia. Nature 2015;518:552-5.

47. Bejar R, Stevenson KE, Caughey B, et al. Somatic mutations predict poor outcome in patients with myelodysplastic syndrome after hematopoietic stem-cell transplantation. J Clin Oncol 2014;32:2691-8.

48. Loghavi S, Wang SA. Defining the boundary between myelodysplastic syndromes and myeloproliferative neoplasms. Surg Pathol Clin 2019;12:651-69.

49. Thota S, Gerds AT. Myelodysplastic and myeloproliferative neoplasms: updates on the overlap syndromes. Leuk Lymphoma 2018;59:803-12.

50. Srour SA, Devesa SS, Morton LM, et al. Incidence and patient survival of myeloproliferative neoplasms and myelodysplastic/ myeloproliferative neoplasms in the United States, 2001-12. Br J Haematol 2016;174:382-96.

51. Vardiman JW, Harris NL, Brunning RD. The World Health Organization (WHO) classification of the myeloid neoplasms. Blood 2002;100:2292-302.

52. Onida F, Kantarjian HM, Smith TL, et al. Prognostic factors and scoring systems in chronic myelomonocytic leukemia: a 
retrospective analysis of 213 patients. Blood 2002;99:840-9.

53. Schuler E, Schroeder M, Neukirchen J, et al. Refined medullary blast and white blood cell count based classification of chronic myelomonocytic leukemias. Leuk Res 2014;38:1413-9.

54. Such E, Germing U, Malcovati L, et al. Development and validation of a prognostic scoring system for patients with chronic myelomonocytic leukemia. Blood 2013;121:3005-15.

55. Goasguen JE, Bennett JM, Bain BJ, et al. Morphological evaluation of monocytes and their precursors. Haematologica 2009;94:994-7.

56. Droin N, Jacquel A, Hendra JB, et al. Alpha-defensins secreted by dysplastic granulocytes inhibit the differentiation of monocytes in chronic myelomonocytic leukemia. Blood 2010;115:78-88.

57. Loghavi S, Curry JL, Garcia-Manero G, et al. Chronic myelomonocytic leukemia masquerading as cutaneous indeterminate dendritic cell tumor: expanding the spectrum of skin lesions in chronic myelomonocytic leukemia. J Cutan Pathol 2017;44:1075-9.

58. Ricci C, Fermo E, Corti S, et al. RAS mutations contribute to evolution of chronic myelomonocytic leukemia to the proliferative variant. Clin Cancer Res 2010;16:2246-56.

59. Cervera N, Itzykson R, Coppin E, et al. Gene mutations differently impact the prognosis of the myelodysplastic and myeloproliferative classes of chronic myelomonocytic leukemia. Am J Hematol 2014;89:604-9.

60. Voglová J, Chrobák L, Neuwirtová R, Malasková V, Straka L. Myelodysplastic and myeloproliferative type of chronic myelomonocytic leukemia--distinct subgroups or two stages of the same disease? Leuk Res 2001;25:493-9.

61. Arber DA, Orazi A. Update on the pathologic diagnosis of chronic myelomonocytic leukemia. Mod Pathol 2019;32: 732-40.

62. Valent $\mathrm{P}$, Orazi A, Savona MR, et al. Proposed diagnostic criteria for classical chronic myelomonocytic leukemia (CMML), CMML variants and pre-CMML conditions. Haematologica 2019;104:1935-49.

63. Geyer JT, Tam W, Liu YC, et al. Oligomonocytic chronic myelomonocytic leukemia (chronic myelomonocytic leukemia without absolute monocytosis) displays a similar clinicopathologic and mutational profile to classical chronic myelomonocytic leukemia. Mod Pathol 2017;30:1213-22.

64. Wassie EA, Itzykson R, Lasho TL, et al. Molecular and prognostic correlates of cytogenetic abnormalities in chronic myelomonocytic leukemia: a Mayo Clinic-French consortium study. Am J Hematol 2014;89:1111-5.

65. Tiu RV, Gondek LP, O’Keefe CL, et al. Prognostic impact of SNP array karyotyping in myelodysplastic syndromes and related myeloid malignancies. Blood 2011;117:4552-60.

66. Itzykson R, Kosmider O, Renneville A, et al. Prognostic score including gene mutations in chronic myelomonocytic leukemia. J Clin Oncol 2013;31:2428-36.

67. Patnaik MM, Vallapureddy R, Yalniz FF, et al. Therapy related-chronic myelomonocytic leukemia (CMML): molecular, cytogenetic, and clinical distinctions from de novo CMML. Am J Hematol 2018;93:65-73.

68. Itzykson R, Kosmider O, Renneville A, et al. Clonal architecture of chronic myelomonocytic leukemias. Blood 2013;121:2186-98.

69. Gelsi-Boyer V, Trouplin V, Roquain J, et al. ASXL1 mutation is associated with poor prognosis and acute transformation in chronic myelomonocytic leukaemia. Br J Haematol 2010;151: 365-75.

70. Patnaik MM, Tefferi A. Cytogenetic and molecular abnormalities in chronic myelomonocytic leukemia. Blood Cancer J 2016; 6:e393.

71. Kuo MC, Liang DC, Huang CF, et al. RUNX1 mutations are frequent in chronic myelomonocytic leukemia and mutations at the C-terminal region might predict acute myeloid leukemia transformation. Leukemia 2009;23:1426-31.

72. Carulli G, Fabiani O, Azzara A. The syndrome of abnormal chromatin clumping in leukocytes. Haematologica 1997;82: 635-6.

73. Invernizzi R, Custodi $\mathrm{P}$, de Fazio $\mathrm{P}$, et al. The syndrome of abnormal chromatin clumping in leucocytes: clinical and biological study of a case. Haematologica 1990;75:532-6.

74. Kurzrock R, Bueso-Ramos CE, Kantarjian H, et al. BCR rearrangement-negative chronic myelogenous leukemia revisited. J Clin Oncol 2001;19:2915-26.

75. Hernández JM, del Cañizo MC, Cuneo A, et al. Clinical, hematological and cytogenetic characteristics of atypical chronic myeloid leukemia. Ann Oncol 2000;11:441-4.

76. Mughal TI, Cross NC, Padron E, et al. An International MDS/MPN Working Group's perspective and recommendations on molecular pathogenesis, diagnosis and clinical characterization of myelodysplastic/myeloproliferative neoplasms. Haematologica 2015;100:1117-30.

77. Patnaik MM, Barraco D, Lasho TL, et al. Targeted next generation sequencing and identification of risk factors in World Health Organization defined atypical chronic myeloid leukemia. Am J Hematol 2017;92:542-8.

78. Gambacorti-Passerini CB, Donadoni C, Parmiani A, et al. Recurrent ETNK1 mutations in atypical chronic myeloid leukemia. Blood 2015;125:499-503.

79. Piazza R, Valletta S, Winkelmann N, et al. Recurrent SETBP1 mutations in atypical chronic myeloid leukemia. Nat Genet 2013;45:18-24.

80. Meggendorfer $M$, Bacher U, Alpermann $T$, et al. SETBP1 mutations occur in $9 \%$ of MDS/MPN and in $4 \%$ of MPN cases and are strongly associated with atypical CML, monosomy 7 , isochromosome $\mathrm{i}(17)(\mathrm{q} 10)$, ASXL1 and CBL mutations. Leukemia 2013;27:1852-60.

81. Faisal M, Stark H, Büsche G, et al. Comprehensive mutation profiling and mRNA expression analysis in atypical chronic myeloid leukemia in comparison with chronic myelomonocytic leukemia. Cancer Med 2019;8:742-50.

82. Meggendorfer M, Haferlach T, Alpermann T, et al. Specific molecular mutation patterns delineate chronic neutrophilic leukemia, atypical chronic myeloid leukemia, and chronic myelomonocytic leukemia. Haematologica 2014;99:e244-6.

83. Gotlib J. How I treat atypical chronic myeloid leukemia. Blood 2017;129:838-45.

84. Maxson JE, Gotlib J, Pollyea DA, et al. Oncogenic CSF3R mutations in chronic neutrophilic leukemia and atypical CML. N Engl J Med 2013;368:1781-90. 
85. Pardanani A, Lasho TL, Laborde RR, et al. CSF3R T618I is a highly prevalent and specific mutation in chronic neutrophilic leukemia. Leukemia 2013;27:1870-3.

86. Wang SA, Hasserjian RP, Fox PS, et al. Atypical chronic myeloid leukemia is clinically distinct from unclassifiable myelodysplastic/ myeloproliferative neoplasms. Blood 2014;123:2645-51.

87. Locatelli F, Niemeyer CM. How I treat juvenile myelomonocytic leukemia. Blood 2015;125:1083-90.

88. Lasho T, Patnaik MM. Juvenile myelomonocytic leukemia - a bona fide RASopathy syndrome. Best Pract Res Clin Haematol 2020;33:101171.

89. Niemeyer CM, Arico M, Basso G, et al. Chronic myelomonocytic leukemia in childhood: a retrospective analysis of 110 cases. European Working Group on Myelodysplastic Syndromes in Childhood (EWOG-MDS). Blood 1997;89:3534-43.

90. Niemeyer CM, Flotho C. Juvenile myelomonocytic leukemia: who's the driver at the wheel? Blood 2019;133:1060-70.

91. Sakashita K, Matsuda K, Koike K. Diagnosis and treatment of juvenile myelomonocytic leukemia. Pediatr Int 2016;58:681-90.

92. Loh ML. Recent advances in the pathogenesis and treatment of juvenile myelomonocytic leukaemia. Br J Haematol 2011;152: 677-87.

93. Bresolin S, De Filippi P, Vendemini F, et al. Mutations of SETBP1 and JAK3 in juvenile myelomonocytic leukemia: a report from the Italian AIEOP study group. Oncotarget 2016;7:28914-9.

94. Sugimoto Y, Muramatsu H, Makishima H, et al. Spectrum of molecular defects in juvenile myelomonocytic leukaemia includes ASXL1 mutations. Br J Haematol 2010;150:83-7.

95. Stieglitz E, Taylor-Weiner AN, Chang TY, et al. The genomic landscape of juvenile myelomonocytic leukemia. Nat Genet 2015;47:1326-33.

96. Sakaguchi H, Okuno Y, Muramatsu H, et al. Exome sequencing identifies secondary mutations of SETBP1 and JAK3 in juvenile myelomonocytic leukemia. Nat Genet 2013;45:937-41.

97. Tartaglia M, Niemeyer CM, Fragale A, et al. Somatic mutations in PTPN11 in juvenile myelomonocytic leukemia, myelodysplastic syndromes and acute myeloid leukemia. Nat Genet 2003;34:148-50.

98. Caye A, Strullu M, Guidez F, et al. Juvenile myelomonocytic leukemia displays mutations in components of the RAS pathway and the PRC2 network. Nat Genet 2015;47:1334-40.

99. Niemeyer CM, Kang MW, Shin DH, et al. Germline CBL mutations cause developmental abnormalities and predispose to juvenile myelomonocytic leukemia. Nat Genet 2010;42: 794-800.

100. Muramatsu H, Makishima H, Jankowska AM, et al. Mutations of an E3 ubiquitin ligase c-Cbl but not TET2 mutations are pathogenic in juvenile myelomonocytic leukemia. Blood 2010;115:1969-75.

101. Manabe A, Yoshimasu T, Ebihara Y, et al. Viral infections in juvenile myelomonocytic leukemia: prevalence and clinical implications. J Pediatr Hematol Oncol 2004;26:636-41.

102. Yoshimi A, Kamachi Y, Imai K, et al. Wiskott-Aldrich syndrome presenting with a clinical picture mimicking juvenile myelomonocytic leukaemia. Pediatr Blood Cancer 2013;60:836-41.

103. Strauss A, Furlan I, Steinmann S, et al. Unmistakable morphology? Infantile malignant osteopetrosis resembling juvenile myelomonocytic leukemia in infants. J Pediatr 2015;167:486-8.

104. Patnaik MM, Tefferi A. Refractory anemia with ring sideroblasts (RARS) and RARS with thrombocytosis (RARS-T): 2017 update on diagnosis, risk-stratification, and management. Am J Hematol 2017;92:297-310.

105. Jeromin S, Haferlach T, Weissmann S, et al. Refractory anemia with ring sideroblasts and marked thrombocytosis cases harbor mutations in SF3B1 or other spliceosome genes accompanied by JAK2V617F and ASXL1 mutations. Haematologica 2015;100: e125-7.

106. Patnaik MM, Lasho TL, Finke CM, et al. Predictors of survival in refractory anemia with ring sideroblasts and thrombocytosis (RARS-T) and the role of next-generation sequencing. Am J Hematol 2016;91:492-8.

107. Jeromin S, Haferlach T, Grossmann V, et al. High frequencies of SF3B1 and JAK2 mutations in refractory anemia with ring sideroblasts associated with marked thrombocytosis strengthen the assignment to the category of myelodysplastic/myeloproliferative neoplasms. Haematologica 2013;98:e15-7.

108. Szpurka H, Jankowska AM, Makishima H, et al. Spectrum of mutations in RARS-T patients includes TET2 and ASXL1 mutations. Leuk Res 2010;34:969-73.

109. Broséus J, Alpermann T, Wulfert M, et al. Age, JAK2(V617F) and SF3B1 mutations are the main predicting factors for survival in refractory anaemia with ring sideroblasts and marked thrombocytosis. Leukemia 2013;27:1826-31.

110. Malcovati L, Della Porta MG, Pietra D, et al. Molecular and clinical features of refractory anemia with ringed sideroblasts associated with marked thrombocytosis. Blood 2009;114:3538-45.

111. DiNardo CD, Daver N, Jain N, et al. Myelodysplastic/ myeloproliferative neoplasms, unclassifiable (MDS/MPN, U): natural history and clinical outcome by treatment strategy. Leukemia 2014;28:958-61.

112. Cannella L, Breccia M, Latagliata R, Frustaci A, Alimena G. Clinical and prognostic features of patients with myelodysplastic/ myeloproliferative syndrome categorized as unclassified (MDS/MPD-U) by WHO classification. Leuk Res 2008;32:514-6.

113. Meggendorfer M, Jeromin S, Haferlach C, Kern W, Haferlach T. The mutational landscape of 18 investigated genes clearly separates four subtypes of myelodysplastic/myeloproliferative neoplasms. Haematologica 2018;103:e192-5.

114. Bose P, Nazha A, Komrokji RS, et al. Mutational landscape of myelodysplastic/myeloproliferative neoplasm-unclassifiable. Blood 2018;132:2100-3.

115. Mangaonkar AA, Swoboda DM, Coltro G, et al. Clinicopathologic characteristics, prognostication and treatment outcomes for myelodysplastic/myeloproliferative neoplasm, unclassifiable (MDS/MPN-U): Mayo Clinic-Moffitt Cancer Center study of 135 consecutive patients. Leukemia 2020;34: 656-61.

116. Coltro G, Mangaonkar AA, Lasho TL, et al. Clinical, molecular, and prognostic correlates of number, type, and functional localization of TET2 mutations in chronic myelomonocytic leukemia (CMML)-a study of 1084 patients. Leukemia 2020;34: 1407-21.

117. Fattizzo B, Serpenti F, Barcellini W, Caprioli C. Hypoplastic 
myelodysplastic syndromes: just an overlap syndrome? Cancers (Basel) 2021;13:132.

118. Bono E, McLornan D, Travaglino E, et al. Clinical, histopathological and molecular characterization of hypoplastic myelodysplastic syndrome. Leukemia 2019;33:2495-505.

119. Choi JW, Fujino M, Ito M. F-blast is a useful marker for differentiating hypocellular refractory anemia from aplastic anemia. Int J Hematol 2002;75:257-60.
120. Sloand EM. Hypocellular myelodysplasia. Hematol Oncol Clin North Am 2009;23:347-60.

121. Skibenes ST, Clausen I, Raaschou-Jensen K. Next-generation sequencing in hypoplastic bone marrow failure: what difference does it make? Eur J Haematol 2021;106:3-13.

122. Babushok DV. A brief, but comprehensive, guide to clonal evolution in aplastic anemia. Hematology Am Soc Hematol Educ Program 2018;2018:457-66. 